\title{
Diffusion Limitation for Atrazine Biodegradation in Soil
}

\author{
Teresa A. Johnson ${ }^{1}$, Timothy R. Ellsworth ${ }^{2}$, Robert J. M. Hudson ${ }^{2}$, Gerald K. Sims ${ }^{3^{*}}$ \\ ${ }^{1}$ Younkin Success Center, Ohio State University, Columbus, USA \\ ${ }^{2}$ Department of Natural Resources and Environmental Sciences, University of Illinois, Urbana, USA \\ ${ }^{3}$ Department of Entomology Plant Pathology and Weed Science, New Mexico State University, Las Cruces, USA \\ Email: "gksims@nmsu.edu
}

Received July 13, 2013; revised August 8, 2013; accepted August 15, 2013

Copyright (C) 2013 Teresa A. Johnson et al. This is an open access article distributed under the Creative Commons Attribution License, which permits unrestricted use, distribution, and reproduction in any medium, provided the original work is properly cited.

\begin{abstract}
Effects of sub-millimeter scale heterogeneity in chemical and microbial distributions on atrazine degradation were examined using Pseudomonas sp. strain ADP introduced into soil at a population mimicking atrazine-adapted soils ( $\sim 2000$ cells $/ \mathrm{g})$, and employing a range of soil water pressures $(-100,-300,-500 \mathrm{kPa})$. Heterogeneous cell distribution was employed in all treatments whereas uniformity of distribution was a variable for atrazine introduction. Two methods of initially distributing atrazine in soil were examined. Proximally-applied atrazine (PAA) was intended to yield elevated atrazine concentrations in the vicinity of the degraders. Dispersed atrazine (DA) was introduced to distribute the chemical uniformly as compared to the distribution of degraders. Both rate and extent of degradation were greater than PAA, regardless of water content, presumably due to proximity of atrazine to degraders. Biodegradation decreased with decreasing water content for both application methods, attributed to decreases in atrazine's effective diffusion. Mineralization of nearly $100 \%$ of DA in soils receiving a heterogeneous inoculum with a greater cell density $\left(\sim 10^{7} \mathrm{cells} / \mathrm{g}\right)$ indicates that biodegradation was limited by the distance atrazine had to diffuse. Results support the hypothesis that enhanced populations of atrazine degraders, as reported elsewhere for atrazine-adapted soils, though heterogeneously distributed, may overcome bioavailability limitations.
\end{abstract}

Keywords: Biodegradation; Environmental; Agriculture; Degradation; Soil; Atrazine; Pseudomonas sp.

\section{Introduction}

The herbicide, atrazine (2-Chloro-4-(ethylamino)-6-(isopropylamino)-s-triazine) has been used for more than fifty years [1], and remains among the most widely used herbicides globally, though recently banned in the European Union in 2004 [2]. Atrazine is considered somewhat persistent, with a reference $t_{1 / 2}$ of $60 \mathrm{~d}$ [3], however, in the case of atrazine-adapted soils, the $t_{1 / 2}$ can be as short as 3.5 days [4-6]. The ecology of atrazine degraders has been examined to use a variety of approaches $[7,8]$, including most recently, stable isotope probing [9]. Though theoretically feasible [10], applications of ${ }^{15} \mathrm{~N}$-DNA-stable isotope probing to examine organisms causing enhanced degradation of atrazine at field rates provided equivocal results, owing to bioavailability limitations [6]. Using RNA-based ${ }^{13} \mathrm{C}$-stable isotope probing, it was shown that the diversity of atrazine degraders varies over millimeter scales in soil [9], though it was necessary to use ${ }^{13} \mathrm{C}$ atrazine at three orders of magnitude beyond the solubility limit to detect these relationships.

\footnotetext{
"Corresponding author.
}

Bioavailability and active degrader populations are ranked among the most influential factors in biodegradation of organic substrates [11]. Adsorbed substrates are typically unavailable to microorganisms, even in aqueous suspensions [12], and soil sorption can similarly reduce availability of herbicides to target weeds [13], reducing effectiveness. Diffusion within micro-porous (impenetrable by bacteria) soil aggregates can further slow sorption kinetics and biodegradation [14-17]. Atrazine degradation can be limited by bioavailability, though the herbicide is less hydrophobic than many herbicides, such as trifluralin [18]. Only $50 \%$ to $80 \%$ of atrazine applied to soil becomes sorbed [19], however detection of the herbicide in drainage water several years following its last application [20,21], suggests atrazine residues exhibit limited bioavailability despite modest sorption, possibly due to physical inaccessibility.

Based on viable counting methods, atrazine degraders are apparently few in number in non-adapted agricultural soils (in some cases undetectable) whereas populations increase to $>10^{3}$ degraders g-soil $^{-1}$ in atrazine-adapted soils [5,22]. Gonod, et al. [23], showed that 2,4-D de- 
graders (typically present at similar or greater numbers than atrazine degraders) are heterogeneously distributed on scales of a few millimeters. At small ( one millimeter) scales, cells would be restricted to the pores of sufficient size to satisfy life support requirements. An inhabitable (to a bacterium) water-filled pore could be assumed to be a spherical volume with a radius of $>1-\mu \mathrm{m}$ [15], while most pores in silt loam soils are $<100-\mu \mathrm{m}$ in size [24] with up to $50 \%$ of the pore volume occurring in pores of $<1-\mu \mathrm{m}$ [15], indicating many unoccupied pores. If we approximate the $>1-\mu \mathrm{m}$ pores as spheres with an average diameter of $10-\mu \mathrm{m}$, then one $\mathrm{g}$ of an atrazine-adapted silt loam soil (30\% porosity and $10^{3}$ degraders) would have $10^{6}$ spherical pores and assuming organisms are uniformly distributed, at most $0.07 \%$ of the pores would contain degraders. In unsaturated soils, larger pores are relatively dry while smaller pores may remain filled, and this network of pores is connected by tortuous paths through water films or pore throats [25]. For a given spatial separation, diffusion of solutes between adjacent pores is slower than within pores due to tortuosity. Thus, degradation of substrates is likely hindered by tortuous diffusion between unoccupied and occupied (by degraders) pores in unsaturated soils, resulting in isolation of a considerable fraction of soluble pesticide from degraders $[26,27]$. Constraints on diffusion imposed by compartmentalization thus limit competition among microbial populations, contributing to the diversity and functional redundancy [28]. Though these relationships are clear from the existing literature, it remains unclear the degree to which heterogeneity on this small scale affects biodegradation kinetics.

Impact of soil compartmentalization on microbial processes also depends on the fraction of water-filled pore space. As water content decreases, diffusion of nonvolatile solutes decreases, thus xenobiotic degradation also tends to decrease with decreasing soil water content [29-31]. Harris [32] concluded that solute diffusion was more likely than osmotic stress to limit microbial processes at low water content. The characteristic spatial scales $(L)$ of concentration gradients are related to the time scales $(T)$ over which they may form or break down and to the effective diffusion coefficient $\left(D_{\text {eff }}\right)$ by a scaling relationship of the form [15]:

$$
T \approx L^{2} / D_{\text {eff }}
$$

This suggests that atrazine persistence may be linked to slow diffusion at relevant spatial scales. The observed persistence of atrazine for time scales considerably longer than a month requires a concentration gradient with a length scale greater than $0.2-1 \mathrm{~mm}$. Spatial variability at this scale and larger likely arise due to non-uniform pesticide application and low degrader populations.

Models of pesticide fate in soil generally assume that there exists a local continuum scale, which is treated as being the same for each of the physical continua, as well as for each "site" or sorptive region within a continuum. Microbial cell density and other variables of interest (substrate concentration, soil water pressure, volumetric water content, etc.) are assumed to be "well-mixed" properties within the local continuum scale. This local continuum scale is commonly referred to as a Representative Elementary Volume, or REV [33]. Biodegradation rates $(R)$ may be expressed as mass per unit time as second-order functions of a local scale degrader population $\left(N_{\text {degrader }}\right)$ and a local scale average bulk concentration of soluble pesticide $\left(C_{\text {bulk }}\right)[15,34]$ :

$$
R=k_{\text {apparent }} \times N_{\text {degrader }} \times C_{\text {bulk }}
$$

The apparent rate coefficient $\left(k_{\text {apparent }}\right)$ depends on the Michaelis-Menten parameters for degradation $\left(V_{\max }\right.$ and $\left.K_{m}\right)$ and the ratio of xenobiotic concentrations at the cell surface $\left(C_{\text {cell }}\right)$ to that in bulk solution $\left(C_{\text {bulk }}\right)$ :

$$
k_{\text {apparent }}=\frac{V_{\max }}{K_{m}} \times \frac{C_{\text {cell }}}{C_{\text {bulk }}}
$$

The latter ratio is typically assumed to be unity, since diffusion limitation is not commonly considered as a factor. Thus, this expression assumes the existence of a local spatial volume, in which the influence of variations in the chemical concentration at microbial cell surfaces, with respect to the average solution concentration within the volume, is assumed negligible. Whether or not this is justified it is difficult to address, as diffusion kinetics are difficult to measure at small scales within soils, and are often inferred from experimental systems in which only overall mass transfer rates are measurable. Despite experimental difficulties, accounting for pesticide diffusion limitation at scales relevant to processes controlling microbial access have potential to improve our understanding of both persistence and enhanced degradation of pesticides [35-37], and may provide insight into the drivers of microbial functional redundancy in soils.

In the present research, experiments were conducted in which the batch scale ratio $C_{\text {cell }} / C_{\text {bulk }}$ was purposefully manipulated to indirectly evaluate whether diffusion at cellular-to millimeter-scales influences atrazine degradation. Two nearly opposite initial conditions were created. In one, soil was saturated with a methanol solution containing atrazine, in order to minimize inter-aggregate heterogeneity by bathing aggregates in a common pool of delivery solvent with limited sorptive retardation (Lee et al., 1993). In this case, the ratio $C_{\text {cell }} / C_{\text {bulk }}$ approached unity when the degrader-containing suspension was subsequently introduced (after solvent had evaporated). In the second method, atrazine was added with degraders, in a volume of water that occupied only $10 \%$ of the total soil pore space, enhancing proximity between substrate 
and degraders. In this case, the ratio $C_{\text {cell }} / C_{\text {bulk }}$ would initially be greater than unity. Initial degradation rates should reflect these differences in the ratio $C_{\text {cell }} / C_{\text {bulk }}$, whereas the subsequent degradation rates should reflect the rate of atrazine diffusion and redistribution. Complete degradation of the pesticide would require it to diffuse from uninhabited to inhabited pores, driven by concentration gradients created by biodegradation.

\section{Materials and Methods}

\subsection{Soil}

Cisne silt loam soil (fine, montmorillonitic, mesic, Mollic Albaqualf) was obtained from the surface of an agricultural field in Brownstown, Illinois, USA. The Cisne is a deep, poorly drained, slowly permeable soil formed in loess on glacial till plains. After air-drying, soil was sieved to obtain 0.4 to $2.0 \mathrm{~mm}$ diameter aggregates, typical at the surface of the site. The soil had a particle density of approximately $2.6 \mathrm{~g} \cdot \mathrm{cm}^{-3}$, and within the incubation vessels, settled to a bulk density of $1.3 \mathrm{~g} \cdot \mathrm{cm}^{-3}$, yielding a total porosity of 0.51 . The average bulk density of individual Cisne soil aggregates within this size class is approximately $\sim 1.7 \mathrm{~g} \cdot \mathrm{cm}^{-3}$ (K. Olson, pers. comm.), yielding an intra-aggregate porosity of 0.36 . The soil had a $\mathrm{pH}$ of 6.0 , an organic carbon content of $1.1 \%$, and a cation exchange capacity of 8.5 cmolc $\mathrm{kg}$-soil $^{-1}$. Extractable $\mathrm{NH}_{4}^{+}-\mathrm{N}$ and $\mathrm{NH}_{3}^{-}-\mathrm{N}$ concentrations were 6.1 and $14.9 \mathrm{mg} \cdot \mathrm{kg}^{-1}$ respectively, as determined by the micro-scale Berthelot method as modified by Sims [38].

\subsection{Chemicals}

Atrazine ( $>99 \%$ purity) was acquired from Chem Service, West Chester, PA. Radiolabeled atrazine [UL-14C] (specific activity $6.3 \times 10^{8} \mathrm{~Bq} \cdot \mathrm{mmol}^{-1} ;>99 \%$ radiochemical purity) was purchased from Sigma Chemical Co., St. Louis, MO. Water and methanol were Optima ${ }^{\mathrm{TM}}$ grade (Fisher Scientific, Pittsburgh, PA). All other chemicals were ACS reagent grade and purchased from either Fisher or EM Science (Gibbstown, NJ).

\subsection{Microorganism and Culture Conditions}

We chose to use Pseudomonas sp. strain ADP (P. ADP, provided by the University of Minnesota, St. Paul) as it has been shown to degrade atrazine constitutively [39], with rates unaffected by exogenous soil inorganic $\mathrm{N}$ sources [40], which can otherwise inhibit atrazine degradation in some soils [41]. The organism has been shown to succeed as a soil inoculum $[39,40]$, and mineralizes the atrazine ring with insignificant metabolite production in soil [40]. The organism was cultured at $22^{\circ} \mathrm{C}-27^{\circ} \mathrm{C}$ in a defined medium containing glucose $\left(0.5 \mathrm{~g} \cdot \mathrm{L}^{-1}\right)$ and atrazine $\left(8.1 \mathrm{mg} \mathrm{N} \cdot \mathrm{L}^{-1}\right)$ as sole N-source [42] with agita- tion at $90 \mathrm{rev} \cdot \mathrm{min}^{-1}$. Prior to each experiment, cells were harvested by centrifugation and washed once with sterile growth medium without a $\mathrm{C}$, or $\mathrm{N}$ source.

\subsection{Soil Degradation Experiments}

Mineralization of ${ }^{14} \mathrm{C}$-labeled atrazine by $P$. ADP was measured in replicate, soil biometers treated as described below. Prior to each experiment, 150-g quantities of airdried soil were immersed in a methanol pretreatment for 24-h. Next, the methanol was allowed to evaporate (approximately 24-h) in a sterile environment and 5-g subsamples of soil were aseptically transferred into sterile 20 -mL scintillation vials $(24-\mathrm{mm}$ ID $\times 8.5-\mathrm{mm} \mathrm{HT})$. After this methanol pre-treatment, the dehydrated soil was sterile and contained only $0.7 \%(\mathrm{w} / \mathrm{w})$ water. To start the experiments, $100 \mu \mathrm{L}$ (14 drops) of aqueous buffer containing $P$. ADP, to deliver 2000 cells $\mathrm{g} \cdot \mathrm{soil}^{-1}$ were applied drop-wise onto the surface of the soil sub-samples, filling approximately $5 \%$ of the total pore space within and between aggregates, or $10 \%$ of the intra-aggregate pore space (Table 1). After the inoculum droplets were rapidly drawn into the dry aggregates that they first contacted (roughly $10 \%$ of the aggregates present), the sample was inverted with a spatula to expose dry soil. Immediately thereafter, enough additional water to bring the soil to the desired water content was added (Table 1) and the soil aggregates were then mixed. The vials were sealed and incubated at $22^{\circ} \mathrm{C}-27^{\circ} \mathrm{C}$, with aeration at each sampling event. The mixing procedure above ensured heterogeneity of $P$. ADP distribution and minimized aggregate destruction.

\subsection{Atrazine Introduction}

During the above sequence, ${ }^{14} \mathrm{C}$-labeled atrazine (ring UL) was introduced at $1 \mu \mathrm{g} / \mathrm{gram}$ soil (oven dry equivalent) $\left(6.3 \times 10^{8} \mathrm{~Bq} \cdot \mathrm{mmol}^{-1}\right)$, using two different procedures to create distinctly different initial distributions of atrazine relative to degraders. In one treatment, herein denoted as dispersed atrazine (DA), atrazine was dissolved in the methanol in which the soil was immersed during the sterilization pretreatment and deposited on the soil particles as the methanol evaporated. Methanol has sufficient surface tension (23 dynes $/ \mathrm{cm}$ ) to wet mineral surfaces, and exhibits Hansen solubility parameters (Van der Waals forces, hydrogen bonds) more similar to water than most solvents [43]. Methanol would be expected to deposit atrazine in both polar and non-polar environments closely resembling the distribution expected for introduction with water [44]. An additional DA treatment was included in which the initial $P$. ADP population was $\sim 10^{7}$ cells $\cdot g^{-1}$. In the second treatment, referred to as proximally applied atrazine (PAA), atrazine was absent from the methanol sterilization treatment, but rather was dis- 
Table 1. Water content of soils used in experiments.

\begin{tabular}{cccc}
\hline Treatment & $\begin{array}{c}\text { Vol. water } \\
\text { content }(\boldsymbol{\theta})^{\mathbf{1}}\end{array}$ & $\begin{array}{c}\text { Centrifuge extracted } \\
\text { water }(\mathbf{v} / \mathbf{v})^{\mathbf{2}}\end{array}$ & $\begin{array}{c}\mathbf{H}_{2} \mathrm{O} \text { pressure } \\
(\mathbf{k P a})^{\mathbf{3}}\end{array}$ \\
\hline Hi- $\boldsymbol{\theta}$ & 0.22 & 0.06 & -100 \\
Me- $\boldsymbol{\theta}$ & 0.16 & 0.02 & -300 \\
Lo- $\boldsymbol{\theta}$ & 0.11 & 0 & -500 \\
\hline
\end{tabular}

${ }^{1}$ Computed using gravimetric water content and bulk density of $1.3 \mathrm{~g} \cdot \mathrm{cm}^{-3}$; ${ }^{2}$ Water recovered by centrifugation (see methods); ${ }^{3}$ Values derived from moisture retention curve determined using standard methods [57].

solved in the $100 \mu \mathrm{L}$ aqueous inoculum solution that was applied to each soil sample (see above).

Mineralization of atrazine was measured by liquid scintillation spectrometry (LSS) of ${ }^{14} \mathrm{CO}_{2}$ trapped on filter paper (treated with $200 \mu \mathrm{L} 0.2 \mathrm{M} \mathrm{NaOH}$ ) suspended from the cap of each vial. A time series was obtained by repeatedly removing and replacing traps over $15-61$ days. On days 15 and 60, atrazine in soil solution was obtained by placing replicate 5 -g samples in $10-\mathrm{mL}$ syringes containing a stainless steel frit $(2-\mu \mathrm{m}$ pore $)$, which were centrifuged at 17,200 g for 20-min and recovered pore water collected for analysis. To measure reversiblysorbed atrazine, centrifuged soil solids were extracted sequentially with $0.01 \mathrm{M} \mathrm{CaCl}_{2}(4 \mathrm{~mL})$ and methanol (4 $\mathrm{mL}$ ) and ${ }^{14} \mathrm{C}$ in the extracts analyzed using LSS [45]. The chemical form of detected radioactivity was confirmed as atrazine in extra replicate samples using HPLC analysis (radioactivity detection) as described by Bichat et al. [40]. The term sorbed atrazine is defined herein as the sum of these two extracts. Unextractable label (bound residue) was quantified by measuring ${ }^{14} \mathrm{CO}_{2}$ released during combustion of extracted soil samples (Biological OxidizerOX500, R. J. Harvey).

Water loss, determined gravimetrically after day-61, did not exceed $5 \%$ of the total water content. In one experiment, water content was increased to $0.24 \mathrm{~mL} \cdot \mathrm{g}^{-1}$ soil on day-18 by adding water without mixing. Aseptic technique was employed throughout the experiments.

\subsection{Statistical Analyses}

Statistical analyses of cumulative mineralization and biodegradation rates consisted of analysis of variance using multivariate repeated-measures and mean comparisons via the SAS system (SAS Institute, Cary, NC), and the data analysis tools in Microsoft Excel. Analyses were run separately for time points before and after addition of water to the treatments at $18 \mathrm{~d}$.

\section{Results and Discussion}

No metabolites were detected, thus mineralization and bound residues were assumed the only degradation products. ${ }^{14} \mathrm{CO}_{2}$ evolution data presented for the dispersed atrazine treatments in Figure 1 show a profound effect of initial P. ADP population on degradation kinetics. Nearly complete degradation of dispersed DA atrazine (up to $98 \%$ in $15 \mathrm{~d})$ when elevated populations of $P$. ADP. $\left(10^{7}\right.$ cells $\cdot \mathrm{g}^{-1}$ ) were introduced into $-100 \mathrm{kPa}$ soil indicates that DA atrazine was immediately bioavailable. Degradation kinetics for the -100 and $-300 \mathrm{kPa}$ treatments were initially identical, but diverged after about $45 \%$ of the atrazine was degraded in the elevated $P$. ADP treatments (Figure 1). The $-300 \mathrm{kPa}$ treatment contained about $75 \%$ as much total water and about $40 \%$ as much centrifuge extracted water as the $-100 \mathrm{kPa}$ treatment (Table 1), and would be expected to exhibit reduced solute transport. These findings were attributed to rapid depletion of atrazine near the cells creating a concentration gradient driving atrazine movement toward the organisms.

Herein, when the initial P. ADP population was 2000 cells.g-soil ${ }^{-1}$, whether atrazine was dispersed (DA) with the methanol or applied in the inoculum (PAA), cumulative mineralization curves at a water content of $-100 \mathrm{kPa}$ were S-shaped (Figure 2), with rates increasing for the first $\sim 15$ days and then slowing (effectively ceasing) between days 40 - 50. No degradation was observed in uninoculated soil. In both application methods, most of the atrazine was not degraded $(88 \%$ in the DA versus $76 \%$ in the PAA) implying that either the atrazine was no longer available to the $P$. ADP, or another factor decreased activity of the degrader. Bound residues accounted for $40 \%-50 \%$ of the applied atrazine, which is consistent with published results for soils exhibiting limited atrazine degradation [46]. Approximately $30 \%$ of the initial atrazine remained bioavailable in dissolved or reversibly sorbed forms on day-61 (Table 2). Measurements of bulk solution atrazine concentrations decreased $\sim 3$-fold between days 18 and 61 while the degradation rates decreased $\sim 10$-fold (Table 2), suggesting the supply rate to the degraders was controlled by a localized pool of atrazine that decreased more than the bulk solution.

A comparison of atrazine degradation in PAA and DA treatments at water contents of $-300 \mathrm{kPa}$ and $-500 \mathrm{kPa}$ during $18 \mathrm{~d}$ incubations also indicated approximately 2 fold greater degradation in the PAA treatments, regardless of water content (Figures 2(b) and (c)). These additional incubations further confirm that the local supply of atrazine was greater in the PAA treatments. At water contents of $-300 \mathrm{kPa}$ and $-500 \mathrm{kPa}$, approximately threeto eight-fold less atrazine respectively was mineralized than during the comparable $18-\mathrm{d}$ period at $-100 \mathrm{kPa}$ in both the DA and PAA treatments (Figure 2), and in contrast to the $-100 \mathrm{kPa}$ treatments, degradation rates remained relatively linear. Differences in cumulative degradation among the water levels were all significant at the $P<0.01$ level. The effect of water content on degra- 
Table 2. Distribution of ${ }^{14} \mathrm{C}$ among phases as measured during experiments.

\begin{tabular}{|c|c|c|c|c|c|c|c|c|c|c|c|}
\hline \multirow{2}{*}{$\begin{array}{l}\text { Atrazine } \\
\text { application }\end{array}$} & \multirow{2}{*}{$\begin{array}{c}\text { Water } \\
\text { pressure } \\
(\mathrm{kPa})^{\dagger}\end{array}$} & \multirow{2}{*}{$\begin{array}{l}\text { Water } \\
\text { content } \\
(\mathrm{ml} / \mathrm{g})^{\dagger}\end{array}$} & \multicolumn{4}{|c|}{ Day 18 of incubation } & \multicolumn{5}{|c|}{ Day 61 of incubation } \\
\hline & & & $\begin{array}{c}{ }^{14} \mathrm{CO}_{2} \\
\text { (\% of initial) }\end{array}$ & $\mathrm{C}_{\mathrm{w}}{ }^{\mathrm{a}}(\mathrm{mg} / \mathrm{L})$ & $\begin{array}{c}\mathrm{C}_{\mathrm{s}}^{\mathrm{a}} \\
(\mathrm{mg} / \mathrm{kg})\end{array}$ & $\begin{array}{c}\mathrm{K}_{\mathrm{d}}^{\mathrm{b}} \\
(\mathrm{L} / \mathrm{kg})\end{array}$ & $\begin{array}{c}{ }^{14} \mathrm{CO}_{2} \\
\text { (\% of initial) }\end{array}$ & $\begin{array}{c}\mathrm{C}_{\mathrm{w}}{ }^{\mathrm{c}} \\
(\mathrm{mg} / \mathrm{L})\end{array}$ & $\begin{array}{c}\mathrm{C}_{\mathrm{s}}^{\mathrm{c}} \\
(\mathrm{mg} / \mathrm{kg})\end{array}$ & $\begin{array}{c}{ }^{14} \mathrm{C}_{\text {Bound }} \\
\text { (\% of initial) }\end{array}$ & $\begin{array}{c}\mathrm{K}_{\mathrm{d}}^{\mathrm{b}} \\
(\mathrm{L} / \mathrm{kg})\end{array}$ \\
\hline PAA & -100 & 0.17 & 12.22 & 0.28 & 0.40 & 1.39 & 24.35 & 0.11 & 0.15 & 39.0 & 1.41 \\
\hline PAA & -300 & 0.12 & 2.78 & 0.39 & 0.62 & 1.58 & 15.51 & 0.19 & 0.22 & 44.0 & 1.18 \\
\hline PAA & -500 & 0.08 & 1.42 & $(0.44)^{\mathrm{d}}$ & 0.65 & & 14.29 & $(0.17)^{\mathrm{d}}$ & $(0.25)^{d}$ & 41.2 & \\
\hline DA & -100 & 0.17 & 5.83 & 0.41 & 0.59 & 1.46 & 12.70 & 0.13 & 0.24 & 49.5 & 1.88 \\
\hline DA & -300 & 0.12 & 1.72 & 0.40 & 0.60 & 1.49 & 5.79 & 0.18 & 0.27 & 43.7 & 1.47 \\
\hline DA & -500 & 0.08 & 0.78 & $(0.37)^{\mathrm{d}}$ & 0.54 & & 6.30 & $(0.21)^{\mathrm{d}}$ & $(0.31)^{\mathrm{d}}$ & 40.9 & \\
\hline
\end{tabular}

${ }^{\mathrm{a}}$ Atrazine concentrations, $C_{w}$, (soil solution) and $C_{s}$ (sorbed) are means of 9 replicates; ${ }^{\mathrm{b}} K_{d}=C_{s} / C_{w}$. $C_{s}$ includes reversibly-sorbed (exchangeable) species only. In abiotic sorption studies on the same soil, a $K_{d}$ of $1.9 \pm 0.7 \mathrm{~L} / \mathrm{kg}$ was obtained; ${ }^{\mathrm{c}}$ Means of 6 replicates for $-100 \mathrm{kPa}$ and $3 \mathrm{replicates}$ for -300 and $-500 \mathrm{kPa}$; ${ }^{\mathrm{d}}$ Dissolved concentration calculated from average $K_{d}$ and $C_{s}$ for this experiment. ${ }^{\dagger}$ Analyses performed by A \& L laboratories, Ft. Wayne, IN. performed as described by Dane and Hopmans [57]. $P_{b} \approx 2.6 \mathrm{~g} \cdot \mathrm{cm}^{-3}$, Aggregate porosity $\approx 0.32$, bulk porosity $\approx 0.51$.

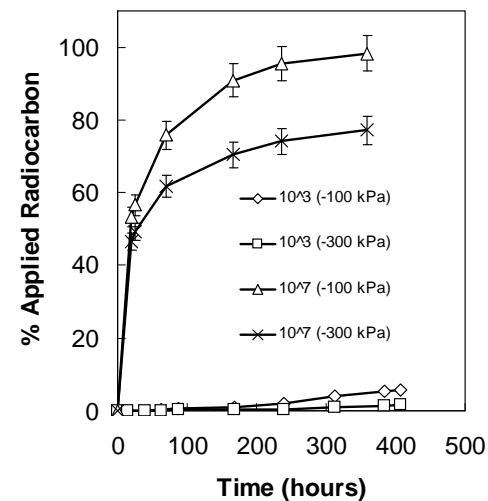

Figure 1. Cumulative mineralization of atrazine using an inoculation density of $10^{3}$ or $10^{7}$ viable cells g-soil ${ }^{-1}$. Atrazine was dispersed (DA) with methanol and soils adjusted to specified water pressures: $-100 \mathrm{kPa}(0.24 \theta),-300 \mathrm{kPa}(0.18$ $\theta)$. Error bars indicate $\sigma$. If there are no error bars shown, bars are smaller than symbol.

dation was not caused by differences in bulk dissolved atrazine concentrations $(\mathrm{Cw})$, which fell within a $10 \%$ range as expected for linear partitioning with the sorbed mass predominant (Table 2).

The difference in degradation rates $(\mathrm{D}, \mu \mathrm{g} / \mathrm{d})$ between $-500 \mathrm{kPa}$ and $-100 \mathrm{kPa}$ incubations $\left(\mathrm{D}_{-500 \mathrm{kPa}}-\mathrm{D}_{-100 \mathrm{kPa}}\right.$ ) is reported in Figure 3 for the PAA and DA application methods. Since degradation rates were initially accelerating in $-100 \mathrm{kPa}$ treatments, $\mathrm{D}_{-500 \mathrm{kPa}}-\mathrm{D}_{-100 \mathrm{kPa}}$ decreases over time. When water was added (without stirring) to achieve $-100 \mathrm{kPa}$ on day 18 in the $-500 \mathrm{kPa}$ incubations, the degradation rate increased $\left(\mathrm{D}_{-500 \mathrm{kPa}}-\right.$ $\mathrm{D}_{-100 \mathrm{kPa}}$ ceased to decrease). Cumulative extents of atrazine degradation in the two PAA treatments after water addition were nearly identical and the rates immediately after wetting were 2- to 5-fold higher than beforehand. Response of degradation rate to rewetting was much more subtle in the case of the DA application method (Figure 3(b)), likely owing to greater distances required

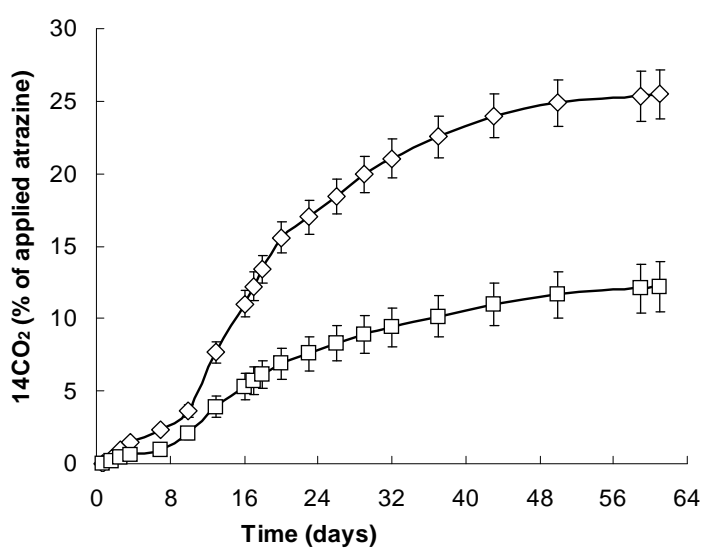

(a)

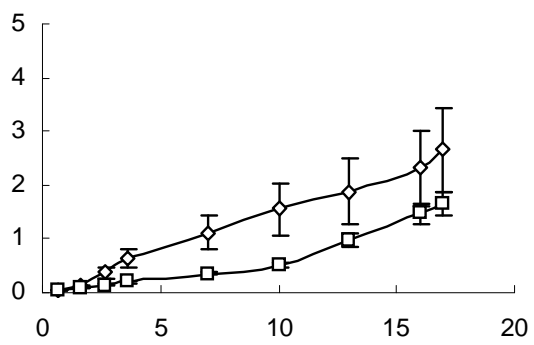

(b)

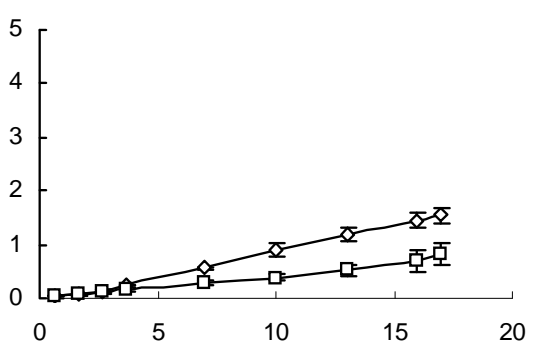

(c)

Figure 2. Cumulative mineralization of atrazine $(\diamond$ proximally applied, $\square$ dispersed) at inoculation density of $10^{3}$ cells g-soil $^{-1}$. (a) $-100 \mathrm{kPa}(0.24 \theta)$, (b) $-300 \mathrm{kPa}(0.18 \theta)$, (c) $-500 \mathrm{kPa}(0.12 \theta)$. Error bars indicate $\sigma$. 


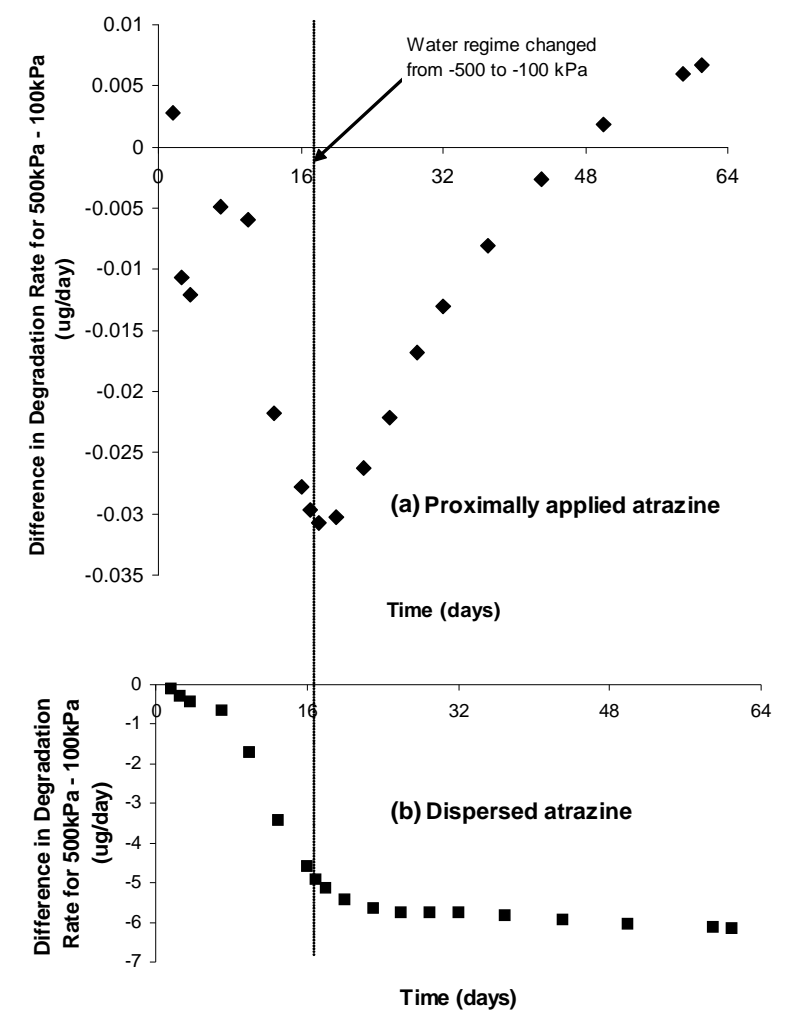

Figure 3. Impact of water regime on atrazine mineralization rate with an initial microbial population of $5 \times 10^{3}$ cells g-soil ${ }^{-1}$. Data are for difference in degradation rates $\left(D_{-500}\right.$ $\mathrm{kPa}-\mathrm{D}_{-100 \mathrm{kPa}}$ expressed in $\mu \mathrm{g}$ atrazine/day) when soil was incubated initially at $-100 \mathrm{kPa}\left(\mathrm{D}_{-100 \mathrm{kPa}}\right)$ versus initially incubated at $-500 \mathrm{kPa}$ and adjusted to $-100 \mathrm{kPa}$ at day 18 (D-500 kPa). Panel (a) shows results for proximally applied atrazine and panel (b) shows results for dispersed atrazine.

for atrazine movement to the cells compared to the PAA treatment. Increases in degradation rates upon water addition to the PAA treatment are consistent with increases in net diffusion.

The general decrease in rates at low water pressures can be readily explained by reduced diffusion. Atrazine diffusion coefficients in these soil systems $\left(D_{\text {eff }}\right)$ were estimated using a semi-empirical solution-phase diffusivity for atrazine [34], the modified Millington-Quirk tortuosity relation, and standard retardation factor to account for reversible adsorption [47], yielding $D_{\text {eff }}$ ranging between $4 \times 10^{-9} \mathrm{~cm}^{2} \cdot \mathrm{s}^{-1}$ at $-100 \mathrm{kPa}$ to $1 \times 10^{-10}$ at $-500 \mathrm{kPa}$. We calculated diffusion-limited initial degradation rates assuming cellular boundary layers are independent and regions containing degraders do not have depleted atrazine concentrations relative to bulk soil. For PAA/ $-500 \mathrm{kPa}$, the observed rate of $\sim 0.4 \mathrm{ng} \cdot \mathrm{g}$-soil ${ }^{-1} \cdot \mathrm{d}^{-1}$ was approximately 10 -fold greater than the calculated diffusion-limited rate of $0.03 \mathrm{ng} \cdot \mathrm{g}-\mathrm{soil}^{-1} \cdot \mathrm{d}^{-1}$. Similarly, the observed initial degradation rates in the PAA/ -300 $\mathrm{kPa}$ and PAA/- $100 \mathrm{kPa}$ treatments were 3- and 1.5-fold above the theoretical maximum rates. Most likely, the
$D_{\text {eff }}$ are too low, especially for the PAA/ $-500 \mathrm{kPa}$ treatment. Bulk empirical $D_{\text {eff }}$ measurements for other triazine herbicides have been reported in the range of $8 \times 10^{-9}$ $\mathrm{cm}^{2} \cdot \mathrm{s}^{-1}$ to $7 \times 10^{-8} \mathrm{~cm}^{2} \cdot \mathrm{s}^{-1}$ in soils with similar volumetric water content and physical properties [48].

Degradation kinetics observed herein using a population $\left(2000\right.$ cells $\left.\cdot \mathrm{g}^{-1}\right)$ meant to simulate an atrazineadapted soil were slower than observed at known adapted sites estimated to harbor $10^{3}$ to $10^{4}$ degraders $\cdot \mathrm{g}^{-1}$, using mineralization of $14 \mathrm{C}$-ring labeled atrazine for MPN detection $[22,49]$. Slower kinetics observed here may be due partly to limited ability of $P$. ADP to adapt to the Cisne soil, or to underestimation of populations by MPN methods used in published literature. Using $P$. ADP as a model for predicting populations at adapted sites $\left(t_{1 / 2}<\right.$ 10 days), approximately $10^{4}$ to $10^{5}$ degraders would be expected per gram, about one or two orders of magnitude greater than values commonly reported from ${ }^{14} \mathrm{C}$-ring labeled atrazine MPN studies, and about one order of magnitude greater than studies using ${ }^{14} \mathrm{C}$-ethyl-labeled atrazine [22]. Counting efficiencies of most MPN methods are reported to underestimate indigenous microbial populations by one or more orders of magnitude, based on activity measurements $[50,51]$, and failed to detect degraders in some non-adapted soils that exhibited significant degradation [22]. Thus, the discrepancies between activity and estimates of microbial counts at atrazine-adapted sites is consistent with the use of viable counting methods. Based on activity, populations in the range of $10^{4}-10^{5}$ cells $^{-1}{ }^{-1}$ at atrazine-adapted sites would be expected to yield MPN data comparable to that reported in the literature, and are in agreement with estimates using quantitative PCR [52]. Increasing the population to $10^{7} \mathrm{~g}^{-1}$ herein produced faster initial degradation $\left(0.013 \mu \mathrm{g} \cdot \mathrm{h}^{-1}\right)$ than reported for natural soil populations, suggesting the two population sizes used here bracket in situ cell densities expected at adapted sites. Results herein support the hypothesis that relatively modest population increases reported for adapted sites [22] are sufficient to overcome diffusion limitations which have been suggested to be important with degrader populations less than $10^{4}$ cells'g-soil $^{-1}$ [53], and may explain the loss of herbicidal effectiveness when atrazine is used repeatedly over a period of many years.

\section{Conclusion}

Soils are often conceptualized as liquid cultures of bacteria, comprised of water contained in habitable pores that surround aggregates containing inaccessible micropores [17], and dissolved xenobiotic outside the micropores is considered bioavailable and homogeneously distributed [54]. Our work suggests that because of tortuous diffusion in unsaturated soils, microorganisms themselves create submillimeter-scale zones depleted of xenobiotic causing 
biodegradation rates to fall below those predicted from bulk concentrations, and the slowness of diffusion limitations effectively isolate a fraction of the xenobiotic from degraders. The occurrence of millimeter-scale isolated regions of pore space is apparently a function of degrader population density. Microbial population effects observed here support the hypothesis that increasing degrader populations to $\sim 10^{5}$ cells $\cdot \mathrm{g}^{-1}$ can be sufficient to overcome diffusion barriers, and may result in strong enhancement of biodegradation, as reported elsewhere for atrazine-adapted sites. Among common herbicides, atrazine is relatively mobile in soil, having a diffusion coefficient only an order of magnitude lower than that reported for one of the most mobile herbicides, 2,4-D [55]. Many herbicides are far less mobile than atrazine (e.g., dinitroanilines exhibit $D_{\text {eff }}$ up to six orders of magnitude lower than atrazine [56]), thus it is expected that submillimeter scale diffusion will limit biodegradation of most soil applied herbicides.

\section{Acknowledgements}

A culture of $P$. ADP and the organism's Michaelis constant for atrazine was provided by M. L. DeSouza. Steve Wente's assistance with statistical analyses is appreciated. This work was partially supported by The Agricultural Research Service, United States Department of Agriculture, project number 3611-12220-006-00D, and salary support for the corresponding author during the writing period was provided by the New Mexico State University Agricultural Experiment Station. The authors have no conflict of interest to declare.

\section{REFERENCES}

[1] H. M. LeBaron, J. E. MsFarland and O. Burnside, "The Triazine Herbicides: A Milestone in the Development of Weed Control Technology," In: H. M. LeBaron, J. E. McFarland and O. Burnside, Eds., The Triazine Herbicides: 50 Years Revolutionizing Agriculture, Elsevier BV, Oxford, 2008, pp. 1-12.

[2] F. Ackerman, "The Economics of Atrazine," International Journal of Occupational and Environmental Health, Vol. 13, No. 4, 2007, pp. 437-444.

[3] R. D. Wauchope, T. M. Butler, A. G. Hornsby, P. M. Augustine-Bekcers and J. P. Burt, "The SCS/ARS/CES Pesticide Properties Database for Environmental Decision Making," Reviews of Environmental Contamination and Toxicology, Vol. 123, 1992, pp. 1-155. doi:10.1007/978-1-4612-2862-2 1

[4] D. L. Shaner and W. B. Henry, "Field History and Dissipation of Atrazine and Metolachlor in Colorado," Journal of Environmental Quality, Vol. 36, No. 1, 2007, pp. 128134. doi:10.2134/jeq2006.0160

[5] J. L. Krutz, D. L. Shanerb, C. Accinelli, R. M. Zablotowicz, and W. B. Henry, "Atrazine Dissipation in s-Triazine-Adapted and Nonadapted Soil from Colorado and
Mississippi: Implications of Enhanced Degradation on Atrazine Fate and Transport Parameters," Journal of Environmental Quality, Vol. 37, No. 3, 2008, pp. 848-857. doi: $10.2134 /$ jeq2007.0448

[6] E. A. Shaffer, G. K. Sims, A. M. Cupples, C. Smyth, J. Chee-Sanford and A. Skinner, "Atrazine Biodegradation in a Cisne Soil Exposed to a Major Spill," International Journal of Soil, Sediment and Water, Vol. 3, No. 2, 2010, pp. $1-26$.

[7] J. Mahía, S. J. González-Prieto, A. Martín, E. Bååth and M. Díaz-Raviña, "Biochemical Properties and Microbial Community Structure of Five Different Soils after Atrazine Addition," Biology and Fertility of Soils, Vol. 47, No. 5, 2011, pp. 577-589. doi:10.1007/s00374-011-0569-x

[8] C. Monard, F. Martin-Laurent, M. Devers-Lamran, O. Lima, P. Vandenkoornhuyse and F. Binet, "atz Gene Expressions during Atrazine Degradation in the Soil Drilosphere," Molecular Ecology, Vol. 19, No. 4, 2010, pp. 749-759. doi:10.1111/j.1365-294X.2009.04503.x

[9] C. Monard, P. Vandenkoornhuyse, B. L. Bot and F. Binet, "Relationship between Bacterial Diversity and Function under Biotic Control: The Soil Pesticide Degraders as a Case Study," The ISME Journal, Vol. 5, 2011, pp. 10481056. doi: $10.1038 /$ ismej.2010.194

[10] A. M. Cupples, E. A. Shaffer, J. C. Chee-Sanford and G. K. Sims, "DNA Buoyant Density Shifts during 15N DNA Stable Isotope Probing," Microbiological Research, Vol. 162, No. 4, 2007, pp. 328-334. doi:10.1016/j.micres.2006.01.016

[11] Y. J. Tang, L. Qi and B. Krieger-Brockett, "Evaluating Factors That Influence Microbial Phenanthrene Biodegradation Rates by Regression with Categorical Variables," Chemosphere, Vol. 59, No. 5, 2005, pp. 729-741. doi:10.1016/j.chemosphere.2004.10.037

[12] E. J. O’Loughlin, S. J. Traina and G. K. Sims, "Effects of Sorption on the Biodegradation of 2-Methylpyridine in Aqueous Suspensions of Reference Clay Minerals," Environmental Toxicology and Chemistry, Vol. 19, No. 9, 2000, pp. 2168-2174. doi:10.1002/etc.5620190904

[13] G. K. Sims, S. Taylor-Lovell, G. Tarr and S. Maskel, "Role of Sorption and Degradation in the Herbicidal Function of Isoxaflutole," Pest Management Science, Vol. 65, No. 7, 2009, pp. 805-810. doi:10.1002/ps. 1758

[14] P. M. Gschwend and S. C. Wu, "On the Constancy of Sediment-Water Partition Coefficients of Hydrophobic Organic Pollutants," Environmental Science and Technology, Vol. 19, No. 1, 1985, pp. 90-96. doi:10.1021/es00131a011

[15] M. Alexander and K. M. Scow, "Kinetics of Biodegradation in Soil," In: B. L. Sawhney and K. Brown, Eds., Reactions and Movement of Organic Chemicals in Soils, ASA and SSSA, Madison, 1989, pp. 243-269.

[16] K. M. Scow and M. Alexander, "Effect of Diffusion on the Kinetics of Biodegradation: Experimental Results with Synthetic Aggregates," Soil Science Society of America Journal, Vol. 56, No. 1, 1992, pp. 128-134. doi:10.2136/sssaj1992.03615995005600010020x

[17] K. M. Scow and J. Hutton, "Effect of Diffusion and Sorption on the Kinetics of Biodegradation: Theoretical Con- 
siderations," Soil Science Society of America Journal, Vol. 56, No. 1, 1992, pp. 119-127. doi:10.2136/sssaj1992.03615995005600010019x

[18] E. Hiller, Z. Krascsenits and S. Cernanský, "Sorption of Acetochlor, Atrazine, 2,4-D, Chlorotoluron, MCPA, and Trifluralin in Six Soils from Slovakia," Bulletin of Environmental Contamination and Toxicology, Vol. 80, No. 5, 2008, pp. 412-416. doi:10.1007/s00128-008-9430-9

[19] D. A. Laird and W. C. Koskinen, "Triazine Soil Interations," In: H. M. LeBaron, J. E. McFarland and O. Burnside, Eds., The Triazine Herbicides: 50 Years Revolutionizing Agriculture, Elsevier, Oxford, 2008, pp. 275-300.

[20] A. R. Isensee, R. G. Nash and C. S. Helling, "Effect of Conventional vs. No-Tillage on Pesticide Leaching to Shallow Groundwater," Journal of Environmental Quality, Vol. 19, No. 3, 1990, pp. 434-440. doi:10.2134/jeq1990.00472425001900030014x

[21] D. D. Buhler, G. W. Randall, W. C. Koskinen and D. L. Wyse, "Atrazine and Alachlor Losses from Subsurface Tile Drainage of a Clay Loam Soil," Journal of Environmental Quality, Vol. 22, No. 3, 1993, pp. 583-588. doi:10.2134/jeq1993.00472425002200030024x

[22] K. Jayachandran, N. B. Stolpe, T. B. Moorman and P. J. Shea, "Application of 14C-Most-Probable-Number Technique to Enumerate Atrazine-Degrading Microorganisms in Soil," Soil Biology and Biochemistry, Vol. 30, No. 4, 1998, pp. 523-529. doi:10.1016/S0038-0717(97)00137-5

[23] L. V. Gonod, C. Chenu and G. Soulas, "Spatial Variability of 2,4-Dichlorophenoxyacetic Acid (2,4-D) Mineralisation Potential at a Millimetre Scale in Soil," Soil Biology \& Biochemistry, Vol. 35, No. 3, 2003, pp. 373-382. doi:10.1016/S0038-0717(02)00287-0

[24] L. Wu, "Pore Size, Particle Size, Aggregate Size, and Water Retention," Soil Science Society of America Journal, Vol. 54, No. 4, 1990, pp. 952-956. doi:10.2136/sssaj1990.03615995005400040002x

[25] M. Tuller, D. Or and L. M. Dudley, "Adsorption and Capillary Condensation in Porous Media: Liquid Retention and Interfacial Configurations in Angular Pores," Water Resources Research, Vol. 35, No. 7, 1999, pp. 1949-1964. doi:10.1029/1999WR900098

[26] P. Duquenne, C. Chenu, G. Richard and G. Catroux, "Effect of Carbon Source Supply and Its Location on Competition between Inoculated and Established Bacterial Strains in Sterile Soil Microcosm," FEMS Microbiology Ecology, Vol. 29, No. 4, 1999, pp. 331-339. doi:10.1111/j.1574-6941.1999.tb00624.x

[27] G. Soulas and B. Lagacherie, "Modeling of Microbial Degradation of Pesticides in Soils," Biology and Fertility of Soils, Vol. 33, No. 6, 2001, pp. 551-557. doi:10.1007/s003740100363

[28] J. Zhou, B. Xia, H. Huang, A. V. Palumbo and J. M. Tiedje, "Microbial Diversity and Heterogeneity in Sandy Subsurface Soils," Applied and Environmental Microbiology, Vol. 70, No. 3, 2004, pp. 1723-1734. doi:10.1128/AEM.70.3.1723-1734.2004

[29] T. A. Johnson, G. K. Sims, T. R. Ellsworth and A. M. Balance, "Effects of Moisture and Sorption on Biodegradation of p-Hydroxybenzoic Acid by Arthrobacter sp.,"
Microbiological Research, Vol. 153, No. 4, 1998, pp. 349-353. doi:10.1016/S0944-5013(99)80049-4

[30] D. R. Shelton and T. B. Parkin, "Effect of Moisture on Sorption and Biodegradation of Carbofuran in Soil," Journal of Agriculture and Food Chemistry, Vol. 39, No. 11, 1991, pp. 2063-2068. doi:10.1021/jf00011a036

[31] M. Mojasevic, C. S. Helling, T. J. Gish and M. A. Doherty, "Persistence of Seven Pesticides as Influenced by Soil Moisture," Journal of Environmental Science and Health, Vol. 31, No. 3, 1996, pp. 469-476. doi:10.1080/03601239609373009

[32] R. F. Harris, "Effect of Water Potential on Microbial Growth and Activity," In: D. M. Kral, et al., Eds., Water Potential Relations in Soil Microbiology, Vol. 9, Soil Science Society of America, Madison, 1981, pp. 23-95.

[33] P. Baveye and C. W. Boast, "Physical Scales and Spatial Predictability of Transport Processes in the Environment," Geophysical Monograph Series, Vol. 108, pp. 261280.

[34] R. P. Schwarzenbach, P. M. Gschwend and D. M. Imboden, "Environmental Organic Chemistry," John Wiley \& Sons, Inc., New York, 1993.

[35] A. M. Cupples, G. K. Sims, R. P. Hultgren and S. E. Hart, "Effect of Soil Conditions on the Degradation of Cloransulam-Methyl," Journal of Environmental Quality, Vol. 29, No. 3, 2000, pp. 786-794. doi:10.2134/jeq2000.00472425002900030014x

[36] S. F. Simoni, A. Schafer, H. Harms and A. J. B. Zehnder, "Factors Affecting Mass Transfer Limited Biodegradation in Saturated Porous Media," Journal of Contaminant Hydrology, Vol. 50, No. 1-2, 2001, pp. 99-120. doi:10.1016/S0169-7722(01)00099-7

[37] L. Y. Wick, T. Colangelo and H. Harms, "Kinetics of Mass Transfer-Limited Bacterial Growth on Solid PAH's," Environmental Science and Technology, Vol. 35, No. 2, 2001, pp. 354-361. doi:10.1021/es001384w

[38] G. K. Sims, "Using the Berthelot Method for Nitrite and Nitrate Analysis," Soil Science Society of America Journal, Vol. 70, No. 3, 2006, p. 1038. doi:10.2136/sssaj2005.04081

[39] R. Mandelbaum, D. Allan and L. Wackett, "Isolation and Characterization of a Pseudomonas sp. That Mineralizes the s-Triazine Herbicide Atrazine," Applied and Environmental Microbiology, Vol. 61, No. 4, 1995, pp. 14511457.

[40] F. Bichat, G. K. Sims and R. L. Mulvaney, "Microbial Utilization of Heterocyclic Nitrogen from Atrazine," Soil Science Society of America Journal, Vol. 63, No. 1, 1999, pp. 100-110. doi:10.2136/sssaj1999.03615995006300010016x

[41] G. K. Sims, "Nitrogen Starvation Promotes Biodegradation of N-Heterocyclic Compounds in Soil," Soil Biology \& Biochemistry, Vol. 38, No. 8, 2006, pp. 2478-2480. doi:10.1016/j.soilbio.2006.01.006

[42] M. Radosevich, J. J. Crawford, S. J. Traina, Y. L. Hao and O. H. Tuovinen, "Degradation and Mineralization of Atrazine by a Soil Bacterial Isolate," Applied and Environmental Microbiology, Vol. 61, No. 1, 1995, pp. $297-$ 
302.

[43] C. M. Hansen, "Hansen Solubility Parameters: A User's Handbook," 2nd Edition, CRC Press Taylor Francis Group, Boca Raton, p. 2007.

[44] T. A. Johnson and G. K. Sims, "Introduction of 2,4-Dichlorophenoxyacetic Acid into Soil with Solvents and Resulting Implications for Bioavailability to Microorganisms," World Journal of Microbiology and Biotechnology, Vol. 27, No. 5, 2010, pp. 1137-1143. doi:10.1007/s11274-010-0560-y

[45] S. Clay and W. Koskinen, "Adsorption and Desorption of Atrazine, Hydroxyatrazine, and s-Glutathione Atrazine on Two Soils," Weed Science, Vol. 38, No. 3, 1990, pp. 262266.

[46] S. Houot, E. Topp, A. Yassir and G. Soulas, "Dependence of Accelerated Degradation of Atrazine on Soil pH in French and Canadian Soils," Soil Biology \& Biochemistry, Vol. 32, No. 5, 2000, pp. 615-625. doi:10.1016/S0038-0717(99)00188-1

[47] W. A. Jury and R. Horton, "Soil Physics," 6th Edition, John Wiley and Sons, Inc., New York, 2004.

[48] A. Walker and D. V. Crawford, "Diffusion Coefficients for Two Triazine Herbicides in Six Soils," Weed Research, Vol. 10, No. 2, 1970, pp. 126-132. doi:10.1111/j.1365-3180.1970.tb00933.x

[49] R. M. Zablotowicz, M. A. Weaver and M. A. Locke, "Microbial Adaptation for Accelerated Atrazine Mineralization Degradation in Mississippi Delta Soils," Weed Science, Vol. 54, No. 3, 2006, pp. 538-547. doi:10.1614/WS-04-179R3.1

[50] K. H. Baker and A. L. Mills, "Determination of the Number of Respiring Thiobacillus Ferrooxidans Cells in Water Samples by Using Combined Fluorescent Antibody-2-(pIodophenyl)-3-(p-Nitrophenyl)-5-Phenyltetrazolium Chlo- ride Staining," Applied and Environmental Microbiology, Vol. 43, No. 2, 1982, pp. 338-344.

[51] L. W. Belser and E. L. Mays, "Use of Nitrifier Activity Measurements to Estimate the Efficiency of Viable Nitrifier Counts in Soils and Sediments," Applied and Environmental Microbiology, Vol. 43, No. 4, 1982, pp. $945-$ 948.

[52] F. Martin-Laurent, L. Cornet, L. Ranjard, J. C. LópezGutiérrez, L. Philippot, C. Schwartz, R. Chassod, G. Catroux and G. Soulas, "Estimation of Atrazine-Degrading Genetic Potential and Activity in Three French Agricultural Soils," FEMS Microbiology Ecology, Vol. 48, No. 3, 2004, pp. 425-435. doi:10.1016/j.femsec.2004.03.008

[53] Y. Comeau, C. W. Greer and R. Samson, "Role of Inoculum Preparation and Density on the Bioremediation of 2,4-D-Contaminated Soil by Bioaugmentation," Applied Microbiology and Biotechnology, Vol. 38, No. 5, 1993, pp. 681-687. doi:10.1007/BF00182810

[54] G. K. Sims and A. M. Cupples, "Factors Controlling Degradation of Pesticides in Soil," Pesticide Science, Vol. 55, No. 5, 1999, pp. 566-614. doi:10.1002/(SICI)1096-9063(199905)55:5<598::AID-PS 962>3.0.CO;2-N

[55] T. Y. Kim, S. S. Park, S. J. Kim and S. Y. Cho, "Separation Characteristics of Some Phenoxy Herbicides from Aqueous Solution," Adsorption, Vol. 14, No. 5, 2008, pp. 611-619. doi:10.1007/s10450-008-9129-6

[56] L. E. Bode, C. L. Day, M. R. Gebhardt and C. E. Goering, "Mechanism of Trifluralin Diffusion in Silt Loam Soil," Weed Science, Vol. 21, 1973, pp. 480-484.

[57] J. H. Dane and J. W. Hopmans, "Water Retention and Storage," In: J. H. Dane and G. C. Topp, Eds., Methods of Soil Analysis, Part 4, Physical Methods, Soil Science Society of America, Madison, 2002, p. 1692. 